\title{
Angioedema, uso de IECA e infección por SARS-CoV-2
}

\author{
Tamara Gómez-Traveso, Raquel Jaso-Tejera, Ana González-Torre-González, Elena Casuso-Sáenz, Nuria Díez-Herrán \\ Servicio de Medicina Interna, Hospital Comarcal de Laredo, Laredo, Cantabria, España
}

Recibido: 12/11/2020

Aceptado: 15/01/2021

En línea: 30/04/2021

Citar como: Gómez-Traveso T, Jaso-Tejera R, González-Torre-González A, Casuso-Sáenz E, Díez-Herrán N. Angioedema, uso de IECA e infección por SARS-CoV-2. Rev Esp Casos Clin Med Intern (RECCMI). 2021 (abril); 6(1): 10-12. doi: 10.32818/reccmi.a6n1a4.

Cite this as: Gómez-Traveso T, Jaso-Tejera R, González-Torre-González A, Casuso-Sáenz E, Díez-Herrán N. Angioedema, use of ACE inhibitors, and SARS-CoV-2 infection. Rev Esp Casos Clin Med Intern (RECCMI). 2021 (April); 6(1): 10-12. doi: 10.32818/reccmi.a6n1a4.

Autor para correspondencia:Tamara Gómez-Traveso. tgtraveso@hotmail.com

\begin{tabular}{l} 
Palabras clave \\
\hline$\triangleright$ Angioedema \\
$\triangleright$ Uso de IECA \\
$\triangleright$ Bradicinina \\
$\triangleright$ Infección por SARS-CoV-2
\end{tabular}

\section{Keywords}

$\triangleright$ Angioedema

$\triangleright$ ACE inhibitors

$\triangleright$ Bradykinin

$\triangleright$ SARS-COV-2 infection

\section{Resumen}

La infección por SARS-CoV-2, al igual que otras infecciones víricas, produce una gran variedad de manifestaciones cutáneas. Sin embargo, el angioedema no es frecuente y se presenta generalmente asociado a urticaria y a síntomas respiratorios. Su aparición tampoco es habitual en pacientes que además están en tratamiento con IECA. Parece que el mecanismo por el cual el virus y los IECA producen angioedema es similar, alterando la regulación de los receptores ACE-2 y aumentando los niveles de bradicinina. Es razonable pensar que el SARS-CoV-2 pudiera actuar como un factor precipitante al combinarse con estos productos.

Abstract
The SARS-CoV-2 infection, as well as other viral infections, can lead to a considerable variety of cutaneous ma-
nifestations. However, angioedema is not usual, generally showing up associated with urticaria and respiratory
symptoms. Its emergence in patients who are under ACE inhibitors is not common. It seems that the mechanism
by which the virus and ACE inhibitors produce angioedema is similar, both causing dysregulation of ACE-2
receptors and increasing bradykinin levels. It is reasonable to believe that SARS-CoV-2 may act as a potential
trigger when combined with the use of these products.

\section{Puntos destacados}

$\triangleright$ El angioedema es raro en pacientes tratados con inhibidores del enzima convertidor de angiotensina. Se presenta generalmente asociado a urticaria y a síntomas respiratorios.

$\triangleright$ La infección por SARS-CoV-2 podría actuar como un factor precipitante.

\section{Introducción}

A medida que se multiplican los casos de infección por SARS-CoV-2, las manifestaciones cutáneas que produce son más evidentes y están mejor establecidas. Sin embargo, el angioedema continúa siendo una forma de expresión poco frecuente de esta infección.

A continuación, se presenta el caso de una paciente en tratamiento con inhibidores de la enzima convertidora de angiotensina (IECA) e infección por SARSCoV-2, siendo el angioedema la única forma de presentación de esta infección vírica.

Mujer de 83 años que acude al servicio de Urgencias de nuestro hospital por un cuadro de 48 horas de evolución de odinofagia, disfagia y dificultad respiratoria.

\section{Caso clínico}

\section{Antecedentes personales}

Presentaba hipertensión arterial, dislipemia, fibrilación auricular permanente y un episodio de pericarditis constrictiva que precisó pericardiectomía en el año 2016, con hipertensión pulmonar severa secundaria. La paciente se encontraba en tratamiento con: enalapril desde hacía aproximadamente 3 años, furosemida, sildenafilo, apixabán, atorvastatina y omeprazol. Además, era alérgica a metamizol.

Refería odinofagia, disfagia, sensación de edema de partes blandas a nivel cervical y dificultad para respirar de 2 días de evolución. Unos días antes de esta clínica presentó diarrea leve con deposiciones blandas, autolimitándose de forma espontánea. No refería fiebre ni tos. No había recibido tratamientos diferentes a los habituales y no había ingerido alimentos sospechosos. Ningún familiar ni persona de su entorno presentaba síntomas similares.

\section{Exploración física}

En la exploración física llamaba la atención la presencia de estridor laríngeo y taquipnea a 24 rpm, con saturación basal medida con pulxioxímetro del 95\%. 
La tensión arterial y la frecuencia cardíaca se encontraban en rangos normales. En la auscultación cardiopulmonar los tonos cardíacos eran arrítmicos, sin soplos y el murmullo vesicular estaba conservado.

La exploración del abdomen fue normal y no se evidenciaron lesiones cutáneas.

\section{Pruebas complementarias}

El estudio analítico mostró linfopenia de 0,7 × 103/ $\mu \mathrm{L}(1,2-5,0)$, alteración de la coagulación con una actividad de protrombina del 61\% (70-120) y elevación de los marcadores de inflamación con VSG 41 mm (1-30), PCR 0,9 mg/dL (<0,5), ferritina 543 ng/mL (10-291) y dímero D 5928 ng/mL (0-500). La función renal, los iones, la troponina, el perfil hepático y las hormonas tiroideas resultaron normales.

El estudio del complemento descartó déficit de C1 inhibidor (C4, C1 q, C1 inhibidor y actividad C1 inhibidor normales). En la gasometría arterial se objetivó $\mathrm{pCO}_{2} 47 \mathrm{mmHg}$ (32-45) y bicarbonato arterial 28,5 mmol/L (21-26), con $\mathrm{pO}_{2}$ y $\mathrm{pH}$ en rango normal. La radiografía de tórax y el ECG no evidenciaron alteraciones relevantes.

Se completó el estudio mediante rinofibrolaringoscopia que reveló edema a nivel lingual, de epiglotis y de los repliegues aritenoepiglóticos, sin compromiso glótico.

\section{Evolución}

Tras confirmarse el angioedema de la vía aérea superior, se inició tratamiento antihistamínico con dexclorfeniramina 6 mg cada 8 horas y corticoideo con metilprednisolona 40 mg cada 12 horas, con mejoría inmediata de la sintomatología. Se suspendió el enalapril aunque su implicación no estaba clara ya que la paciente llevaba tomándolo varios años.

Horas más tarde la PCR del frotis nasofaríngeo para SARS-CoV-2 resultó positiva. Se añadió al tratamiento azitromicina 500 mg al día, hidroxicloroquina 400 mg cada 12 horas y acetilcisteína 600 mg cada 12 horas según el protocolo vigente en ese momento en nuestro hospital. Además, se pautó enoxaparina a dosis anticoagulantes.

Posteriormente la paciente continuó evolucionando favorablemente, con mejoría sintomática en las siguientes horas y no volvió a presentar más episodios de angioedema.

\section{Diagnóstico}

Angioedema posiblemente relacionado con infección por SARS-CoV-2.

\section{Discusión y conclusión}

La infección por SARS-CoV-2, al igual que otras infecciones víricas, produce una gran variedad de manifestaciones cutáneas. Se han descrito erupciones maculo-papulosas, lesiones urticariformes, exantemas vesiculosos, lesiones acro-isquémicas, livedo-reticularis o necrosis ${ }^{1}$. Sin embargo, el angioedema no es frecuente y existen pocos casos publicados en la literatura, generalmente precedidos o seguidos de sintomatología respiratoria y asociados a urticaria o prurito ${ }^{2-4}$.

La aparición de angioedema sin urticaria es inusual, y únicamente existe otro caso descrito similar al nuestro en el que el angioedema no se acompa- ña de otras lesiones cutáneas ni de clínica respiratoria ${ }^{5}$. Tampoco es habitual la aparición de angioedema en pacientes tratados con IECA e infectados por el SARS-CoV-2, existiendo tan solo 2 casos publicados en el momento actual ${ }^{5,6}$.

El mecanismo por el cual el SARS-CoV-2 produce angioedema es desconocido. Una explicación razonable se basaría en la gran afinidad que tiene este virus por los receptores de la enzima convertidora de angiotensina ॥ (ACE-2), presentes en los pulmones, los riñones o el corazón, pero también en la lengua y en las glándulas salivales ${ }^{7}$, que causa un descenso de la actividad de esta enzima y el consiguiente aumento de los niveles de angiotensina II que impedirían la degradación de la bradicinina, un potente vasodilatador que además aumenta la permeabilidad vascular, desencadenando el angioedema.

En prácticamente todos los casos publicados hasta la fecha, al igual que en el nuestro, la respuesta al tratamiento con antihistamínicos o corticoides fue excelente $e^{2,3,46}$ y se consiguió la remisión del angioedema en pocos días. Conociendo estos resultados, y hasta que no dispongamos de nuevos estudios, debemos considerar estos fármacos como el tratamiento de elección en el angioedema por SARS-CoV-2.

Por otro lado, el angioedema relacionado con la administración de IECA está mejor documentado, apareciendo en el 0,1-0,7\% de los pacientes tratados ${ }^{8}$. Habitualmente aparece en las primeras semanas de su administración, aunque se han descrito casos en los que ocurre tras años de tratamiento. Suele localizarse en labios y lengua, seguidos de faringe y laringe, siendo infrecuente la afección de manos, pies, genitales o aparato digestivo. Su asociación con urticaria o prurito es excepcional. Aunque el mecanismo por el cual se produce no se conoce con exactitud, existen evidencias de que el aumento de bradicinina juega un papel importante.

La enzima convertidora de angiotensina (ECA) es la encargada del catabolismo de la bradicinina, por tanto, su inhibición impediría la degradación de esta sustancia, favoreciendo su acúmulo y, en consecuencia, el aumento de la permeabilidad vascular y el edema. Su diagnóstico es fundamentalmente clínico ya que no existe ninguna prueba de laboratorio específica, confirmándose al comprobar la remisión del angioedema tras la suspensión del IECA.

Los corticoides y antihistamínicos no suelen ser efectivos, siendo la base del tratamiento la retirada del fármaco. Se han propuesto diferentes terapias con eficacia todavía por comprobar, como el ácido traxenámico, el concentrado de C1 inhibidor, el icatibant o el plasma fresco congelado, que también podrían ser útiles en casos graves de angioedema por SAR-CoV-2 que no responden a la administración de antihistamínicos o glucocorticoides ${ }^{5}$.

Por tanto, parece que IECA y SARS-CoV-2 presentan un mecanismo de acción similar al alterar la regulación de la ECA y aumentar los niveles de bradicinina. Es razonable pensar que el SARS-CoV-2 pudiera actuar como factor precipitante del angioedema, al igual que ocurre con otros virus o bacterias, sobre todo si se combina con IECA?

Aunque, como se ha comentado anteriormente, el angioedema es una forma de presentación poco frecuente de la infección por SAR-CoV-2, es importante considerarlo como una manifestación más de este virus y estar alerta para identificarla precozmente, aun en ausencia de urticaria o síntomas respiratorios. Así no solo se detecta de forma temprana la infección por este nuevo virus, sino que también se pueden instaurar rápidamente medidas que protejan la vía aérea e iniciar un tratamiento específico. Además, se debe valorar suspender la administración del IECA para evitar un posible efecto sinérgico con el virus ${ }^{8}$. 


\section{Bibliografía}

1. Galván Casas C, Català A, Carretero Hernández G, Rodríguez-Jiménez $P_{\text {, }}$ Fernández-Nieto D, Rodríguez-Villa Lario A, et al. Classification of the cutaneous manifestations of COVID-19: a rapid prospective nationwide consensus study in Spain with 375 cases. Br J Dermatol. 2020; 183(1): 71-77. doi: 10.1111/bjd.19163

2. Hassan K. Urticaria and angioedema as a prodromal cutaneous manifestation of SARS-CoV-2 (COVID-19) infection. BMJ Case Rep. 2020; 13(7): e236981. doi: 10.1136/bcr-2020-236981.

3. Abasaeed Elhag SA, Ibrahim H, Abdelhadi S. Angioedema and urticaria in a COVID-19 patient: A case report and review of the literature. JAAD Case Rep. 2020; 6(10): 1091-1094. doi: 10.1016/j.jdcr.2020.07.042.

4. Adeliño R, Andrés-Cordón JF, Aracelis De La Cruz Martínez C. Acute urticaria with angioedema in the setting of coronavirus disease 2019.
J Allergy Clin Immunol Pract. 2020; 8(7): 2386-2387. doi: 10.1016/j. jaip.2020.04.061

5. Grewal E, Sutarjono B, Mohammed I. Angioedema, ACE inhibitor and COVID-19. BMJ Case Rep. 2020 Sep 9;13(9):e237888. doi: 10.1136/bcr-2020237888.

6. Cohen AJ, Difrancesco MF, Solomon SD, Vaduganathan M. Angioedema in COVID-19. Eur Heart J. 2020; 41(34): 3283-3284. doi: 10.1093/eurheartj/ ehaa452.

7. Xu H, Zhong L, Deng J, Peng J, Dan H, Zeng X, et al. High expression of ACE2 receptor of 2019-nCoV on the epithelial cells of oral mucosa. Int J Oral Sci. 2020; 12(1): 8. doi: 10.1038/s41368-020-0074-x.

8. Makani H, Messerli FH, Romero J, Wever-Pinzon O, Korniyenko A, Berrios RS, et al. Meta-analysis of randomized trials of angioedema as an adverse event of renin-angiotensin system inhibitors. Am J Cardiol. 2012; 110(3): 383-91. doi: 10.1016/j.amjcard.2012.03.034 